\title{
Intraplate seismic events off Sumatra: 3-D source evolution
}

\author{
B.L.N. Kennett ${ }^{1}$, A. Gorbatov ${ }^{2} \&$ S. Fishwick ${ }^{3}$ \\ ${ }^{1}$ Research School of Earth Sciences, The Australian National University, Canberra ACT 2601, Australia \\ (Brian.Kennett@anu.edu.au) \\ ${ }^{2}$ Geoscience Australia, GPO Box 389, Canberra ACT 2600, Australia \\ ${ }^{3}$ University of Leicester, Leicester, U.K.
}

\begin{abstract}
Four large, dominantly strike-slip, earthquakes have occurred in recent years in the Wharton Basin off the coast of Sumatra. The southernmost was the Mw 7.9 event on 2000 June 18, followed by the largest known intraplate earthquake - the Mw 8.6 event on 2012 April 11, with an Mw 8.2 'aftershock' within a few hours. The most recent Mw 7.8 event on 2016 March 2 happened in an area with no previously recorded large earthquake. For each event we have undertaken analysis of the high-frequency energy radiation as a function of time, using a suite of global stations with good azimuthal control, so that we can map out source evolution in three-dimensions. Each of the events involves a component of conjugate faulting. The largest energy emission links to near north-south features reflecting seafloor topography, with linking east-west rupture. High-frequency radiation is emitted through the full thickness of the lithosphere in the main part of the event. As frequency is reduced there is a distinct change in radiation characteristics, though migration of energy emission to depth is common. Significant energy release occurs at depths where deformation would be expected to be ductile, suggesting differences between instantaneous and long-term rheology. The complex behaviour recognised in the 2012 great earthquakes looks to be a feature of strike-slip events in this zone off the Sumatran subduction zone.

Each of the events occurs in a region where surface wave tomography models show slightly lower shear wavespeed than their surroundings. These contrasts suggest changes in the physical parameters of the Indo-Australian plate in the area of breakup. The conjugate ruptures in response to an oblique stress-field form part of a diffuse zone of deformation associated with the impending divorce between the Indian and Australian components of the plate.
\end{abstract}

Keywords: Earthquake source observations, Body waves, Seismic tomography. 


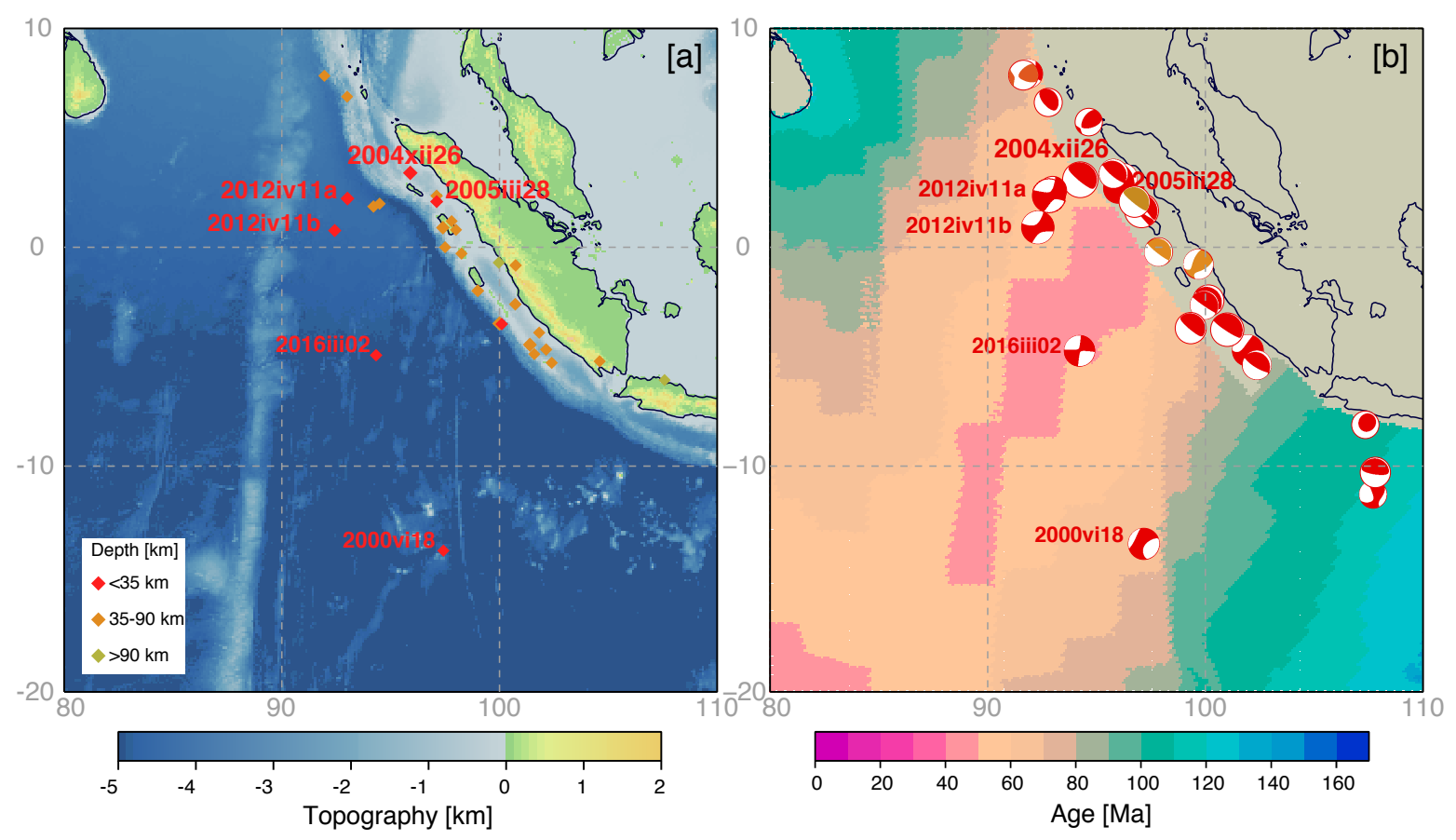

Figure 1. The major seismic events in the Wharton basin, and their relation to lithospheric age. (a) Historical and instrumental events with M>7.5 from the GEM and ISC catalogues, with the recent large Wharton Basin and subduction zones events labelled, on a background of sea floor topography (b) Global CMT solutions since 1990 superimposed on the sea floor age distribution.

\section{INTRODUCTION}

\subsection{Wharton Basin intraplate events}

The Wharton Basin off the coast of Sumatra has been the site of a number of large strike-slip earthquakes in recent years, including the largest known intraplate event - the Mw 8.6 earthquake of 2012 April 11. This suite of events is associated with a broad band of diffuse internal deformation of the Indo-Australian plate as a consequence of the collision of greater India with Eurasia, whilst subduction continues under Indonesia. The consequent plate-boundary stresses (e.g., Delescluse et al. 2012) induce strike-slip faulting in the intraplate deformation zone, even close to the trench where outer-rise extension is typically observed in other subduction environments.

On 2016 March 2 a Mw 7.8 event ruptured in the northwestern Wharton Basin about $600 \mathrm{~km}$ southwest of the Sumatran subduction zone (Figure 1). This intraplate strike-slip event lies south of the Wharton Ridge former spreading centre (Lay et al. 2016). Somewhat further south in the Wharton Basin a Mw 7.9 earthquake occurred on 2000 June 18 west of the Investigator Fracture Zone (Robinson et al. 2001, Abercrombie et al. 2003). To the north of the Wharton Ridge on 2012 April $11 \mathrm{Mw} 8.6$ and 8.2 earthquakes (Figure 1) ruptured a mix of north-south and east-west trending strike slip faults. These Mw 8+ events have been extensively analysed (e.g., Duputel et al. 2012, Satriano et al. 2012, Meng et al. 2012, Yue et al. 2012, Ishii et al. 2013, Wei et al. 2013, Hill et al. 2015). 
The lithospheric age range spanned by the large Wharton Basin earthquakes is from around 50 Ma for the 2012 events, to around 70 Ma for the 2000 event (Figure 1). Irrespective of what class of thermal model is employed for the evolution of the oceanic lithosphere away from a spreading ridge, the lithospheric thickness defined by the $1300^{\circ} \mathrm{C}$ isotherm is between 90 and $100 \mathrm{~km}$. Whereas, the $1000^{\circ} \mathrm{C}$ isotherm lies between 55 and $65 \mathrm{~km}$. The variations in shear wavespeed thus lie within the oceanic lithosphere, in a broad zone around the fossil spreading centre that appears to enlarge with depth.

For most oceanic earthquakes the centroid, point-source, representation lies above the $600^{\circ} \mathrm{C}$ isotherm (McKenzie et al. 2005). The centroid depths for both the Mw 8+ events of 2012 from the Global Centroid Moment Tensor catalogue (gCMT) were rather deep (46 km and $55 \mathrm{~km}$ ). Such centroid depths require slip up to and beyond the $800^{\circ} \mathrm{C}$ isotherm. However, Duputel et al. (2012) performed a moment tensor inversion using very long period waves that suggests shallower centroids in the 30-40 km range. Deep slip in the 2012 earthquakes, down to at least $60 \mathrm{~km}$ depth, is supported by both finite-fault inversion (Wei et al. 2013, Hill et al. 2015) and modelling of GPS displacements (Hill et al., 2015). Abercrombie \& Aderhold (2016) have examined the behaviour of events with Mw above 6.0 in this region and conclude that although many earthquakes are consistent with a thermal limit to the depth of slip, large magnitude earthquakes may be able to rupture zones that are typically aseismic and possibly beyond the inferred transition to ductile failure.

In this work we examine the source processes for the large oceanic earthquakes in the Wharton Basin and their relation to lithospheric structure. We employ energy projection for the higher frequency portions of seismograms across the full global network to get complete azimuthal coverage and a good range of epicentral distances. This enables us to track the evocentre for each event, i.e. the point of maximum energy emission, as a function of spatial position and time (Kennett et al., 2014b).

\subsection{Shear wavespeed variations in the Wharton Basin}

The oceanic region offshore from Sumatra shows rather distinctive variations in shear wavespeed in surface wave tomography results, compared with the rest of the Indian ocean. Building on the results from Fishwick (2010) and Fishwick \& Rawlinson (2012) for the African and Australian continents, waveform data for Rayleigh waves on over 58,000 paths have been exploited to produce a model covering these continents and the Indian Ocean. In a second stage, a subset of these data $(19,417$ path-specific velocity models) focused on the northern Indian Ocean and Indonesian region are incorporated into higher resolution tomographic models, providing a new 3-D image of the shear velocity structure around the Wharton Basin area. In Figure 2 we display the absolute shear wavespeed from this model for map views at $50 \mathrm{~km}$ and $75 \mathrm{~km}$ depth, with the locations of the major earthquakes superimposed. We note that at $50 \mathrm{~km}$, the epicentres of the large Wharton Basin events lie either in a zone of reduced velocity (2012 events)compared with the surroundings or at the edge of gradients into lower shear wavespeed (2000 and 2016 events). At $75 \mathrm{~km}$ depth all the event epicentres in the Wharton Basin lie in zones with shear wavespeed less than $4.5 \mathrm{~km} / \mathrm{s}$. The western zone of reduced wavespeeds starting at $90^{\circ} \mathrm{E}$ is associated with the Ninety East Ridge, a hot-spot track that appears 


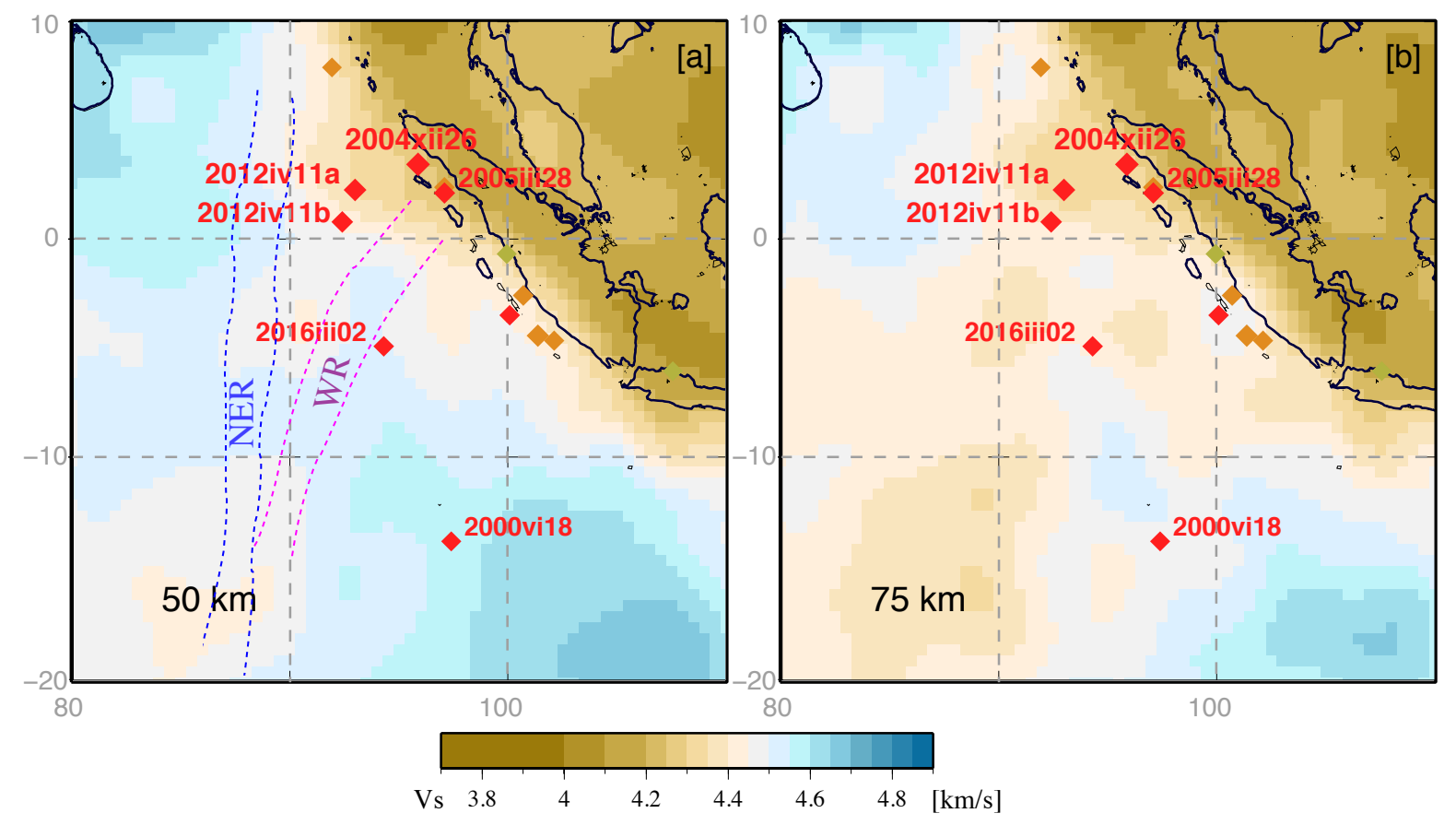

Figure 2. Shear wavespeed from the new surface wave tomography model, showing map views at $50 \mathrm{~km}$ and $75 \mathrm{~km}$ depth. The location of the major seismic events in the Indonesian region around Sumatra since 1984 are also marked. NER - Ninety East Ridge. WR - Wharton Rise (former spreading centre)

to mark a mechanical boundary in the Indian Ocean. Similar features in the Wharton Basin appear in the global surface-wave tomography study of Schaeffer \& Lebedev (2013), with clear S velocity reductions at $80 \mathrm{~km}$ depth. Even though the number of events is small, it is intriguing that all the large oceanic events in this region lie in zones of reduced $\mathrm{S}$ wavespeed.

\subsection{Projection methods}

The use of back-projection methods from dense networks of seismic stations has made a major contribution to the elucidation of the complex behaviour of seismic events since the great Sumatra-Andaman event of 2004 (e.g., Ishii et al. 2005, Meng et al. 2012). Most studies have concentrated on the exploitation of a single group of seismic stations, or comparisons of projection results from different groups of stations. Resolution can be enhanced by exploiting two or more networks (Kiser \& Ishii, 2012). Roessler et al. (2010) have demonstrated the way in which results from multiple arrays at longer periods can be combined to improve spatial resolution.

Rather than using very large groups of stations that cover a narrow azimuth range, an alternative approach is to exploit the global network of broad-band stations to achieve full azimuthal coverage and hence strong spatial localisation in the source area. Pioneered by Walker \& Shearer (2009) for the Mw 7.9 Denali event in Alaska, this approach has been extended by Kennett et al. (2014a,b) who have demonstrated that resolution of event behaviour can be achieved in 3-D.

Most of the approaches to back-projection emphasise coherence in the waveforms employed. At 


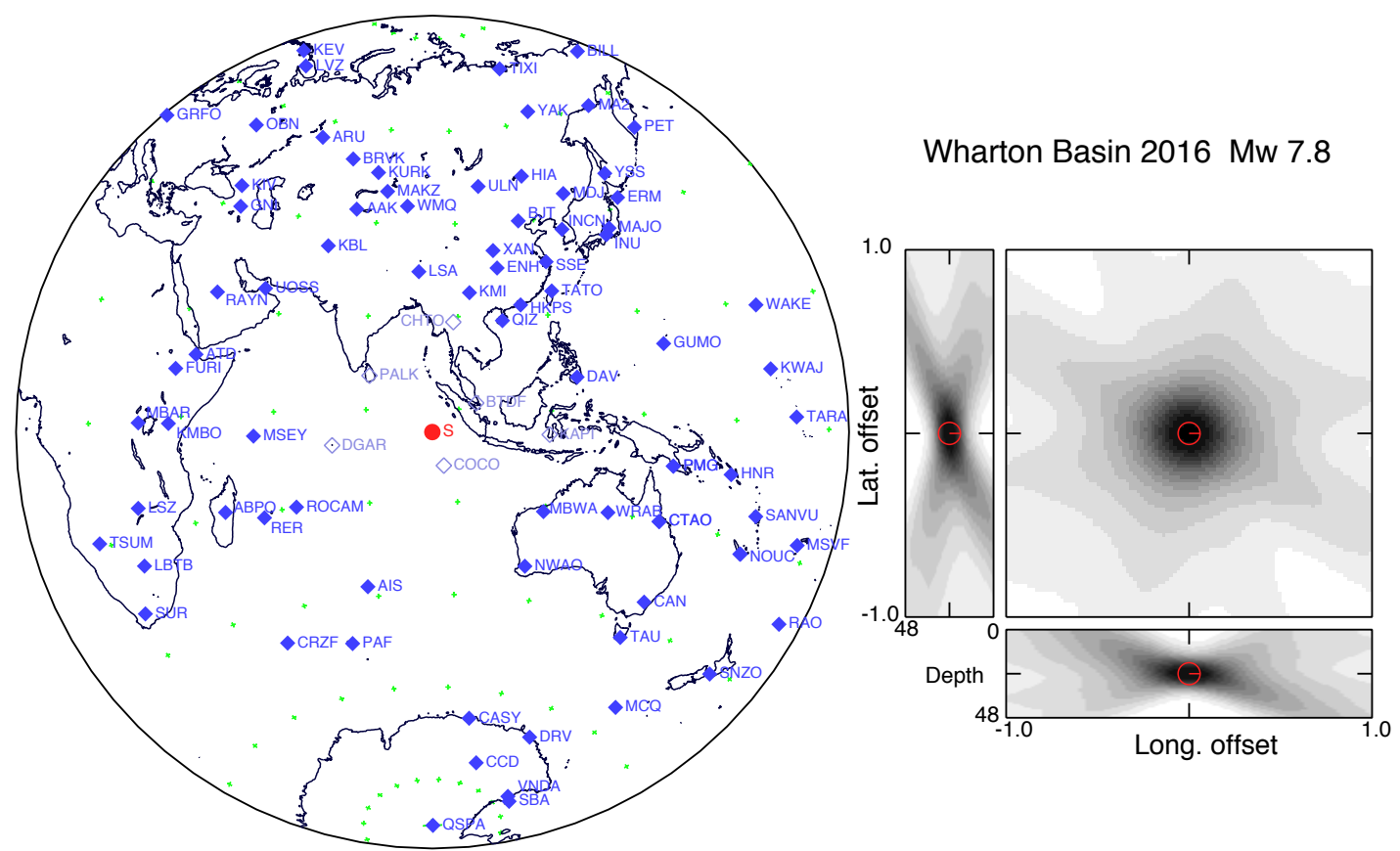

Figure 3. The spatial resolution achievable for the 2016 March 2 event in the Wharton Basin using stations in the Global Seismic Network in the range from $30^{\circ}$ to $90^{\circ}$ epicentral distance. In the left panel the station distribution is displayed in a linear polar projection about the hypocentre; stations closer than $30^{\circ}$ are shown in light blue. In the right panel we show the effective spatial resolution for evocentre estimation at the target point with cross-sections at constant depth, latitude and longitude. The central red symbol marking the target point has a diameter of $12.5 \mathrm{~km}$. The energy resolution function is contoured with 16 equal grey increments.

the global scale this pushes attention to relatively low frequencies. Indeed, with a wide azimuthal span we can expect variations in waveform shape associated with, e.g., directionality in event rupture. The approach adopted by Kennett et al. (2014b) is to work with energy projection from the global stations and map out the evolution of the locus of maximum energy emission with time in 3-D (the evocentre). This global analysis can be applied for events where dense networks are not available, either because of the range to the event or because the event occurred before the advent of such networks. Because attention is focused on energy, there are no problems associated with the polarity of arrivals.

When projected back to the source, constructive interference occurs where many contributions from different stations overlap. The patch of maximal concentration becomes more localised when a broad range of azimuths is available, and there is a similar but weaker effect with variation in incidence angle as a function of epicentral distance. With full azimuthal coverage, and a good span of epicentral distances it is possible to achieve good spatial resolution in 3-D (Kennett et al. 2014b). In consequence the evocentre results provide a useful supplement to work using back-projection from dense arrays that have very limited depth discrimination. A broad spread of epicentral distances also helps to spread out the pattern of 'virtual sources' at the surface corresponding to the reflection points of depth phases (see Section 2.1).

A good estimate of the attainable spatial resolution can be obtained by looking at the mapping 
of segments of seismograms into the vicinity of a target point (Kennett et al. 2014b). When the time segments are aligned based on the travel times from the target, they map back to a band around the target, which is inversely proportional to the slowness for the path. The superposition of the mapped isochronal bands from all the stations employed indicates the potential resolution. In our event analysis we use $4 \mathrm{~s}$ time windows advanced by $2 \mathrm{~s}$ intervals, so that the dominant influence comes from this time window, with a modest influence from the signal band employed (provided this lies above 0.25 $\mathrm{Hz})$.

In Figure 3 we illustrate the spatial resolution attainable for the 2016 March 2 event in the Wharton Basin, using stations beyond $30^{\circ}$ epicentral distance. With the $4 \mathrm{~s}$ sliding windows and the good distribution of stations across the globe, resolution is concentrated in a zone about $15 \mathrm{~km}$ across in all spatial dimensions - a little larger than the red target symbol. We can therefore expect to be able to resolve changes in the depth of energy emission during the course of the event. We use a similar configuration of stations for all four events, and so the resolution estimates are very similar in all cases.

The ak135 model (Kennett et al. 1995) is used as reference throughout for the travel times from any target point to the many different stations. As in normal hypocentral analysis, absolute depth estimates are likely to be distorted due to the differences in structure between ak135 and that of the oceanic lithosphere near the source, but depth progression will be reliable. In particular the thicker crust of ak135 at $35 \mathrm{~km}$ compared with the much thinner oceanic crust, even allowing for overlying water, means that the depth span is stretched near the surface. Below the crust the results from ak135 can be expected to have a systematic shift of about $20 \mathrm{~km}$ to greater depth.

\section{ENERGY PROJECTION AND EVOCENTRES}

The hypocentre represents the point of initial energy emission from an event. Strong azimuthal control is required to achieve accurate locations. We extend the concept of tracking the points of maximum energy emission (evocentres) as a function of time, using the high-frequency part of the seismograms. We employ the same station distribution criteria as for hypocentral determination, but now exploit the seismic waveforms rather than phase arrivals.

The calculation scheme we employ for the evocentres is summarised as an Algorithm. The first step is to extract the travel time residual for each station relative to the hypocentre determined with the ak135 model. We apply time corrections for 3-D structure using these residuals with opposite sign to shift the seismograms at the stations. Thus, in principle, the very first energy should emerge from the hypocentre when using the ak135 model for passage times.

We then establish a search zone surrounding the event hypocentre, and discretize this into $0.05 \mathrm{x}$ $0.05 \mathrm{deg} \times 10 \mathrm{~km}$ voxels. We use the same set of 3-D corrections for all locations within the assigned grid. Because we work with $4 \mathrm{~s}$ time windows along the seismic traces, the results are not sensitive to minor variations in structural corrections.

We start the spatial search for the evocentre in the vicinity of the hypocentre at the onset time, and then as time increases enlarge the domain searched. In this work we have used an expansion rate of $10 \mathrm{~km} / \mathrm{s}$, faster than any rupture but allowing for jumping of rupture between fault segments. For 
Algorithm: Evocentre evaluation scheme (expanded from Kennett et al. 2014b)

- Determine station residuals from ak135 for hypocentre

- Apply as 3D alignment corrections throughout

- Normalise seismograms

- Time Loop

$\triangle$ Extract $4 \mathrm{~s}$ window on seismograms

$\triangle$ Space Loop

$\diamond$ For each 0.05 x $0.05 \mathrm{deg} \times 10 \mathrm{~km}$ voxel

$\diamond$ Calculate travel times to stations

$\diamond$ Align seismograms for emission point

* Determine stacked energy over all stations

$\diamond$ Select site of maximum energy as evocentre

$\triangle$ Advance time window $2 \mathrm{~s}$

the centre of each voxel, we calculate the $P$ phase travel times to each of the stations and introduce the appropriate propagation delays to stack the energy of the seismogram segments. We produce an energy stack result for each voxel and seek the maximum across the spatial grid as our best estimate of the evocentre.

We build the energy estimator from filtered and normalised seismograms $\left\{u_{j}\right\}$ at the station set $\left\{\mathbf{x}_{j}\right\}$, for a postulated source at location $\mathbf{x}_{k}$ with initiation time $T$ after onset, as a stack of integrals over the time interval $\delta \mathrm{t}$ :

$$
\mathcal{E}_{k}(T)=\sum_{j} \int_{0}^{\delta t} \mathrm{~d} \tau w(\tau) u_{j}^{2}\left(T+t_{j k}+\tau\right) .
$$

Here $t_{j k}$ is the traveltime from $\mathbf{x}_{k}$ to $\mathbf{x}_{j}$, including the 3-D corrections, and $w(t)$ is a tapered window function. The best estimate of the location of maximum energy emission, across the stations employed, is then extracted as

$$
\mathbf{x}_{e}(\mathrm{~T})=\mathbf{x}\left[\max _{k} \mathcal{E}_{k}(T)\right] \text {. }
$$

The offset time $T$ is initially set as 0 , and then progressively incremented by $\delta t$ with a sequence of evocentres estimated to chart the progress of the energy emission by the seismic source.

In the applications presented below we work with $4 \mathrm{~s}$ time windows progressively advanced by a step of $2 \mathrm{~s}$. We employ two different frequency bands. The high-frequency band uses bandpass filtering with corners at 0.8 and $4.0 \mathrm{~Hz}$. Whereas, the intermediate-frequency band has corners at 0.2 and 1.0 $\mathrm{Hz}$. We have also applied station weighting to suppress the influence of a few stations with limited signal-to-noise ratio.

Because we map the location of maximum energy emission as a function of time, we see a partial picture of rupture behaviour. Unilateral rupture can be readily mapped, and also jumps to a new rupture location. The case of bilateral rupture is more complicated because there is the possibility of the point 

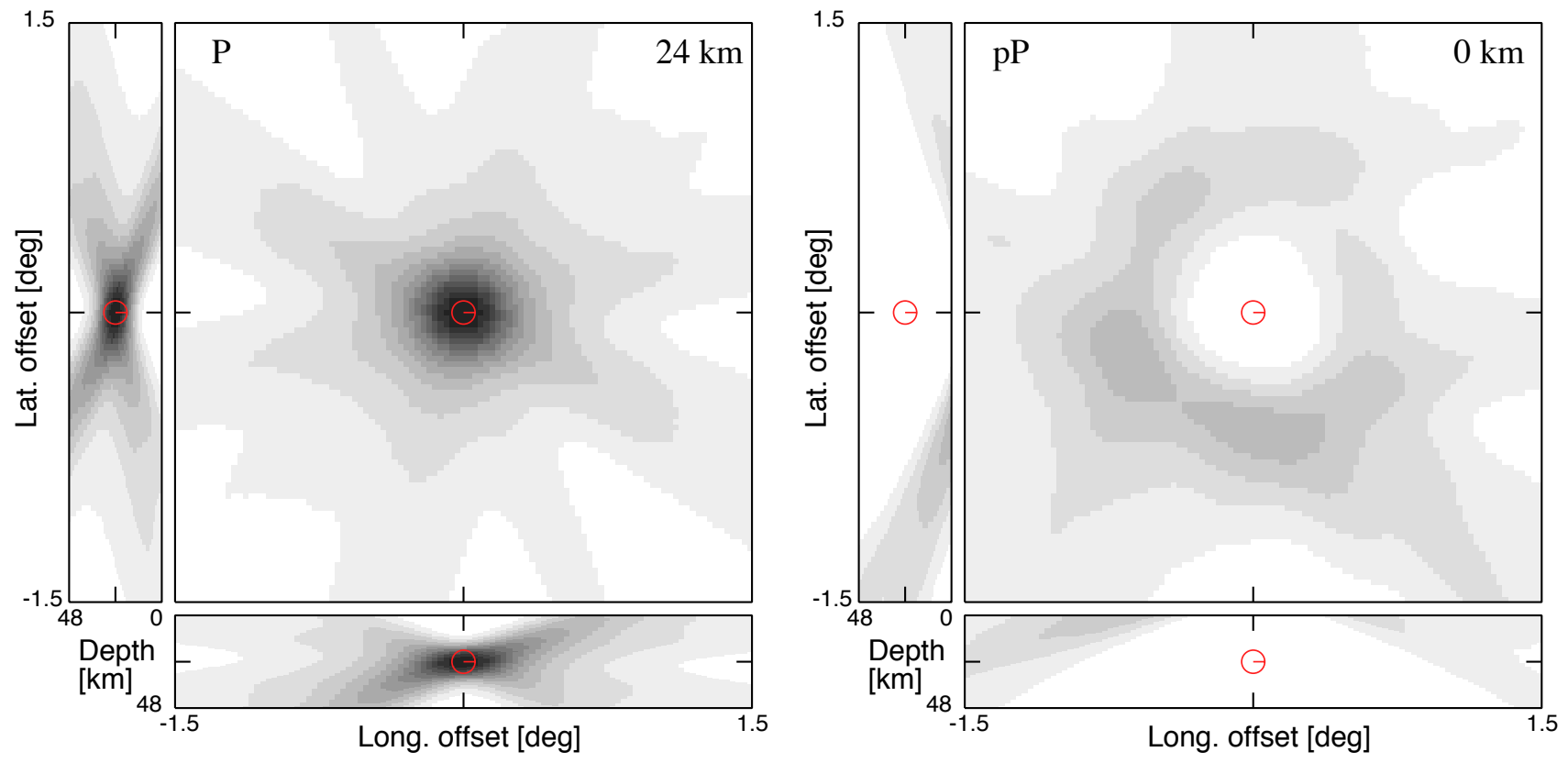

Figure 4. Comparison of spatial resolution patterns for the 2016 March 2 event in the Wharton Basin using the stations in the Global Seismic Network in the range from $30^{\circ}$ to $90^{\circ}$ epicentral distance. The left panel shows the results for $\mathrm{P}$ phases on a slice through the hypocentre. The right panel shows a map view at the surface displaying the ring of virtual sources produced by the $\mathrm{pP}$ phase when it is interpreted as a $\mathrm{P}$ arrival. Both figures are constructed with the same set of 16 equal grey increments for energy.

of maximum energy emission switching from one end of the evolving rupture front to the other. In this case the evocentres will not have a simple spatial progression in time (see also Section 2.2). Nevertheless, it is often possible to map out the behaviour effectively, as in the study of the Mw 8.1 Macquarie Ridge event in 2004 (Kennett et al. 2014a).

\subsection{Depth phase contributions}

In standard back-projection analysis based on a constant depth slice, deeper energy emission will tend to be mapped closer to the network, since the travel times are shorter for deeper sources. Migration of energy emission to depth can then give a distorted picture of the rate of rupture propagation. For our scenario where there is full azimuthal coverage, depth phase energy produces a ring of "virtual sources at the surface that are weaker than the true source at depth. As a result depth phase energy is diffused, but could still have contamination effects if energy emission is occurring in the neighbourhood of a zone of strong "virtual sources".

The energy in $\mathrm{pP}$ can be associated with a mirror source lying above the surface, back projection cannot converge to the true location, and so gives rise to a ring of effective sources at the surface. For sP the mirror source is more complicated, but a similar result emerges. In our evocentre analysis we do attempt to separate PP or Sp energy and hence it will be treated simply as P energy with a later arrival time. 


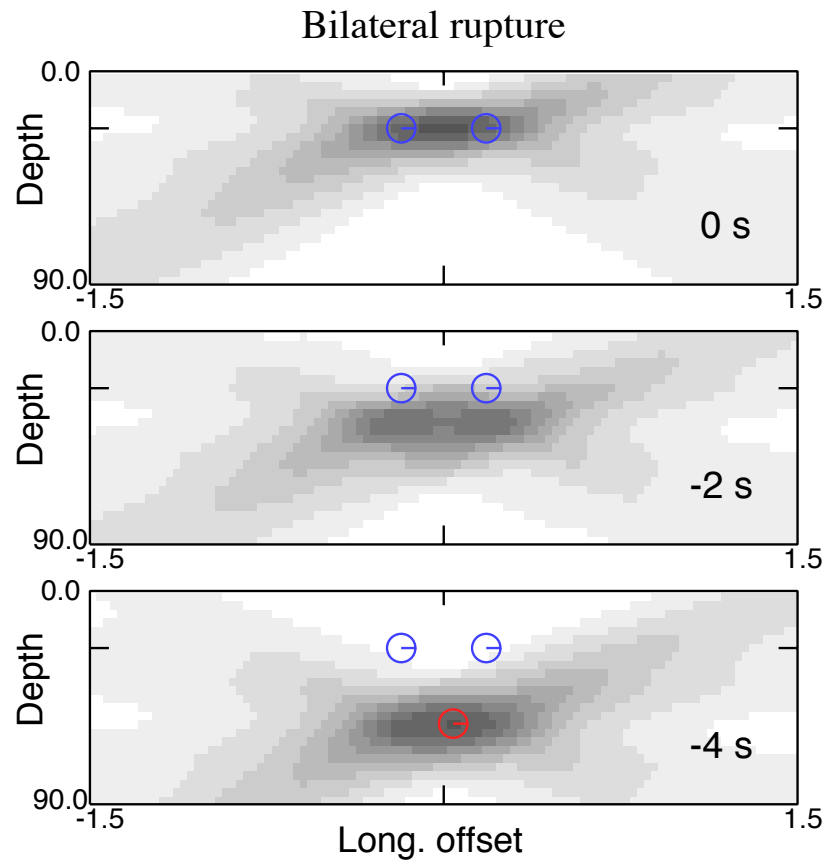

Figure 5. Illustration of the coalescence of back projected energy from a bilateral source leading to an effective source below the true location and at an earlier time.

In Figure 4 we show a comparison of spatial resolution tests for the 2016 March 2 event, with the $\mathrm{P}$ phases as in Figure 3, and the the case where pP phases are treated as if they came from a source of $\mathrm{P}$ waves with the $\mathrm{pP}$ travel time. The contour intervals are the same in both the panels of Figure 4 . The area mapped is larger than in Figure 3, with a span of $3^{\circ}$ rather than $2^{\circ}$.

The map view for $\mathrm{P}$ is taken at the hypocentral depth $(24 \mathrm{~km})$, whereas the view for $\mathrm{pP}$ is at the surface, sampling a weak ring of 'virtual sources' corresponding to the interference of surface reflections on their way to the various stations. At the hypocentral depth of $24 \mathrm{~km}$ the ring is more diffuse and well separated from the source itself.

Thus because of the broad spread of azimuths and epicentral distances used in the evocentre analysis with the global network, contamination effects from depth phases will be markedly reduced compared with the situation for a single dense network. Nevertheless there is a possibility that the interference of depth phases with emissions from depth could push the apparent point of energy emission to somewhat shallower depth, and this could even be displaced to the maximum point of the ring of virtual sources.

\subsection{Bilateral rupture}

The evocentre procedure gives unambiguous results in the case of unilateral rupture, since then there is a single clear point of energy release. However, the situation is more complicated for bilateral rupture. In some case bilateral effects can be detected by an oscillation of the point of maximum energy release between the two ends of the evolving rupture. 
If, however, the energy release at the ends of the rupture is evenly balanced then the situation is more complex. It is now possible for the point of apparent maximum energy release to occur at depth below the midpoint of the rupture, and earlier than the true time (see Figure 5). The characteristics of such an effect would be (a) very little migration in the horizontal position of the evocentres, but (b) a rather rapid migration in depth.

There is little to distinguish such an evocentre progression due to bilateral effects from a true migration of the rupture to depth. However, the rapidity of change and extension to depths well below the expected base of the lithosphere $(60-75 \mathrm{~km})$ are possible markers. Such effects are seen in the group of off-Sumatran events.

\section{MARCH 2 EVENT Mw 7.8}

We first consider the recent Mw 7.82016 March 2 event that lies about $500 \mathrm{~km}$ to the southwest of the subduction zone along the west side of Sumatra (Figure 1). The centroid depth is quite deep at around $40 \mathrm{~km}$. Lay et al. (2016) have used back-projection of high-frequency $P$ waves from European and Australian stations, and finite fault analysis using teleseismic $P$ and $S H$ waveforms coupled with analysis of Love wave directivity to examine the source character. They suggest a bilateral rupture on a north-south trending fault with a relatively short length of around $70 \mathrm{~km}$, and a total duration of about $35 \mathrm{~s}$, indicating relative slow rupture at $\leq 2 \mathrm{~km} / \mathrm{s}$.

In Figure 6 we contrast evocentre estimates for both the high-frequency $(0.8-4.0 \mathrm{~Hz})$ and intermediate-frequency $(0.2-1.0 \mathrm{~Hz})$ bands. We display the results with a map view and projections onto orthogonal sections marked by the dashed grey lines. Above each panel we display the time evolution of the maximum energy at the evocentre location. We see immediate differences in both the spatial distribution and relative energy emission in the two frequency bands. An alternative representation of the behaviour with the aid of a 3-D perspective view is shown in Figure A1 in the Appendix.

The high-frequency results (Figure 6a) indicate that much of this radiation occurs on the north-south fault plane identified by Lay et al. (2016) with a progression to greater depth at later times. The total duration of significant energy emission is less than $40 \mathrm{~s}$. Early evocentres lie to the east of the main fault plane suggesting a component of conjugate faulting. A similar pattern of east-west progression of the evocentres for early times is seen for the intermediate-frequency results (Figure 6a), though again this represents only a modest component of the total energy emission. In contrast to the high-frequency results, the main intermediate energy emission is on an extension of the fault plane to the south, suggesting that some rupture occurred over a larger zone than mapped by the finite-fault analysis of Lay et al. (2016). Once again we see an apparent progression of energy emission to depth in this southern cluster of evocentres.

The presence of an east-west conjugate component to the faulting is consistent with the back-projection results presented by Lay et al. (2016) for both the European and Australian station groups. The European results have a modest projection to the east as well as a main north-south component. The Australian results indicate a dominant east-west trend, but the limited azimuth range 
(a)
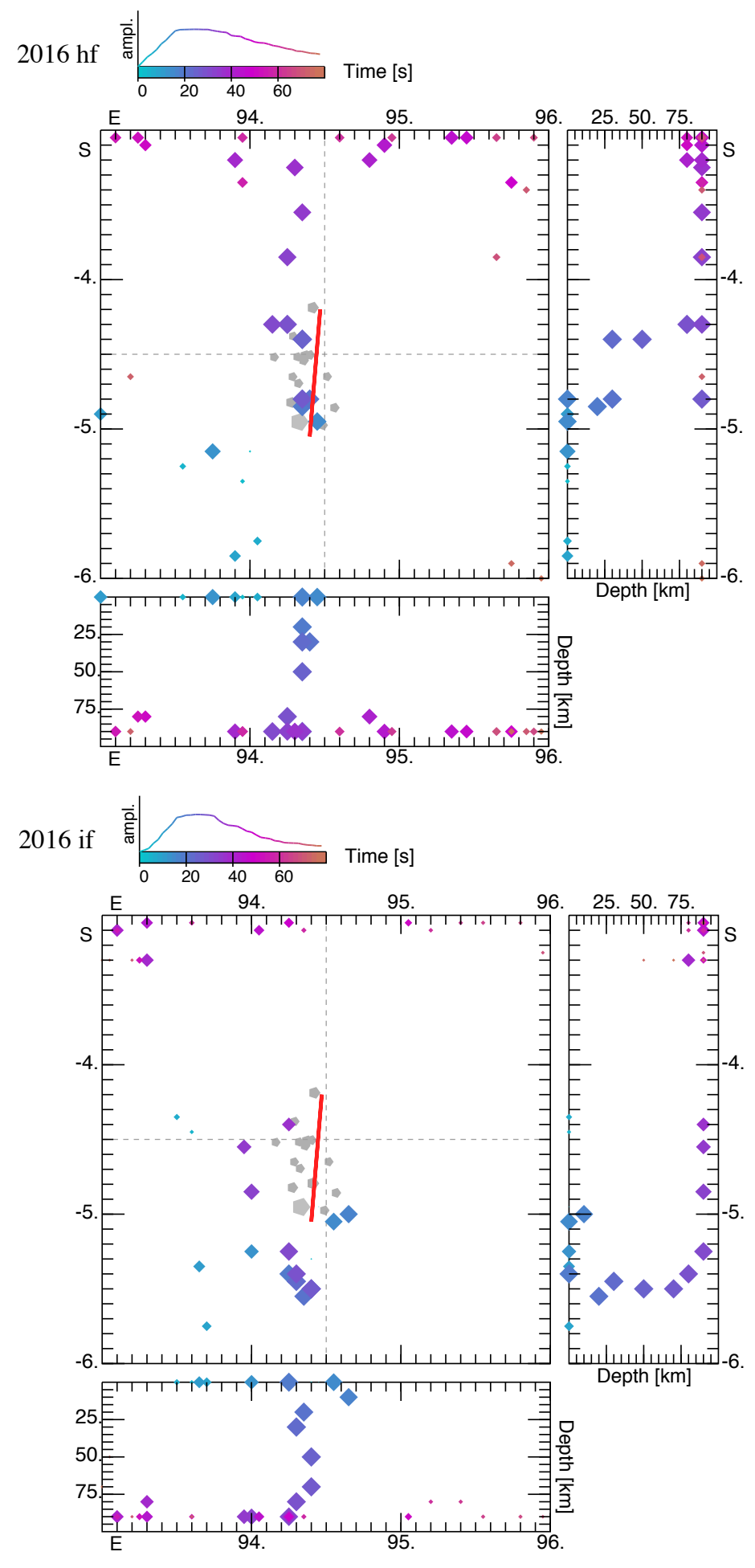

Figure 6. Map and cross-section view of energy projection results for the Mw 7.8 event on 2016 March 2: (a) high frequency band 0.8-2.0 Hz; (b) intermediate frequency band 0.2-1.0 Hz. The evocentres are colour coded as function of time, and scaled by the size of the estimated energy for the window. The red fault plane is taken from the study of Lay et al. (2016). The distribution of the maximum energy at the evocentre as a function is displayed above each panel, together with the colour coding used for identifying evocentres with time. 
covered by these stations precludes a definitive result. With the full azimuth control of the global stations set, illustrated in Figure 3, we are able to separate the conjugate components in the evocentre analysis.

When interpreting the estimated depths of the evocentres we have to be wary of shifts induced by the arrivals of other phases such as $p P, s P$. Such interference can be deleterious if only a narrow span of azimuths is considered, but with full azimuthal coverage the effect of a depth phase misinterpreted as $\mathrm{P}$ is a ring of virtual sources at the surface (see Section 2.1). Thus there is a tendency to spatial spread in possible points of apparent energy emission rather than any migration of evocentres to depth.

In the intermediate frequency band the progression of evocentres to depth is both rapid and has little horizontal displacement. From the results of section 2.2, this behaviour suggests that the actual rupture was bilateral within the lithosphere. The likely depth for the maximal energy release in the intermediate frequency band is around $15-25 \mathrm{~km}$, which is only a little deeper than in the long-period solution presented by Lay et al. (2016)

As noted above all our results use the ak135 model as reference, so control on absolute depth is limited, but relative depths should be reliable. The apparent depth scale down to $35 \mathrm{~km}$ is likely to be somewhat stretched, and so depth migration in this zone may well be exaggerated.

The evocentre results suggest that rupture occurs through the entire lithosphere, with significant energy emission at depth, possibly associated with cracking at the base of the lithosphere even through this lies in a zone where ductile behaviour would normally be expected. As in many other events we see separation between different frequency components of the rupture. The finite-fault analysis of Lay et al. (2016) favours relatively shallow low-frequency emission, which would be surrounded by the high-frequency emission on the main fault plane identified here. Presumably these high-frequency effects are associated with minor asperities at the edges of the main slip zones. The intermediate-frequency results clearly identify the presence of conjugate faulting, and suggest that rupture also occurred over a somewhat longer zone than mapped with low-frequency waves.

Energy release closer to the subduction zone starts within $40 \mathrm{~s}$ of the onset of the main event for both high-frequency and intermediate frequency bands. Most of these evocentres are mapped to the edge of the search area and are likely to be associated with shallower emission to the north outside the search zone.

\section{JUNE 18 EVENT Mw 7.9}

The Mw 7.9 event on 2000 June 18 occurred well into the interior of the Indo-Australian plate about $1000 \mathrm{~km}$ away from the Sumatran subduction zone (Figure 1), and is located on the edge of a zone of reduced shear wavespeed at $75 \mathrm{~km}$ depth (Figure 2). In Figure 7 we display the results of the evocentre analysis in a similar configuration to Figure 6, including the NNW oriented fault plane suggested by Abercrombie et al. (2003). As for the 2016 event we see considerable complexity in the processes of energy emission reflected in the differences between the results for the high-frequency and intermediate-frequency bands. An alternative perspective view of the evocentre results is shown in Figure A2 in the Appendix. 
(a)
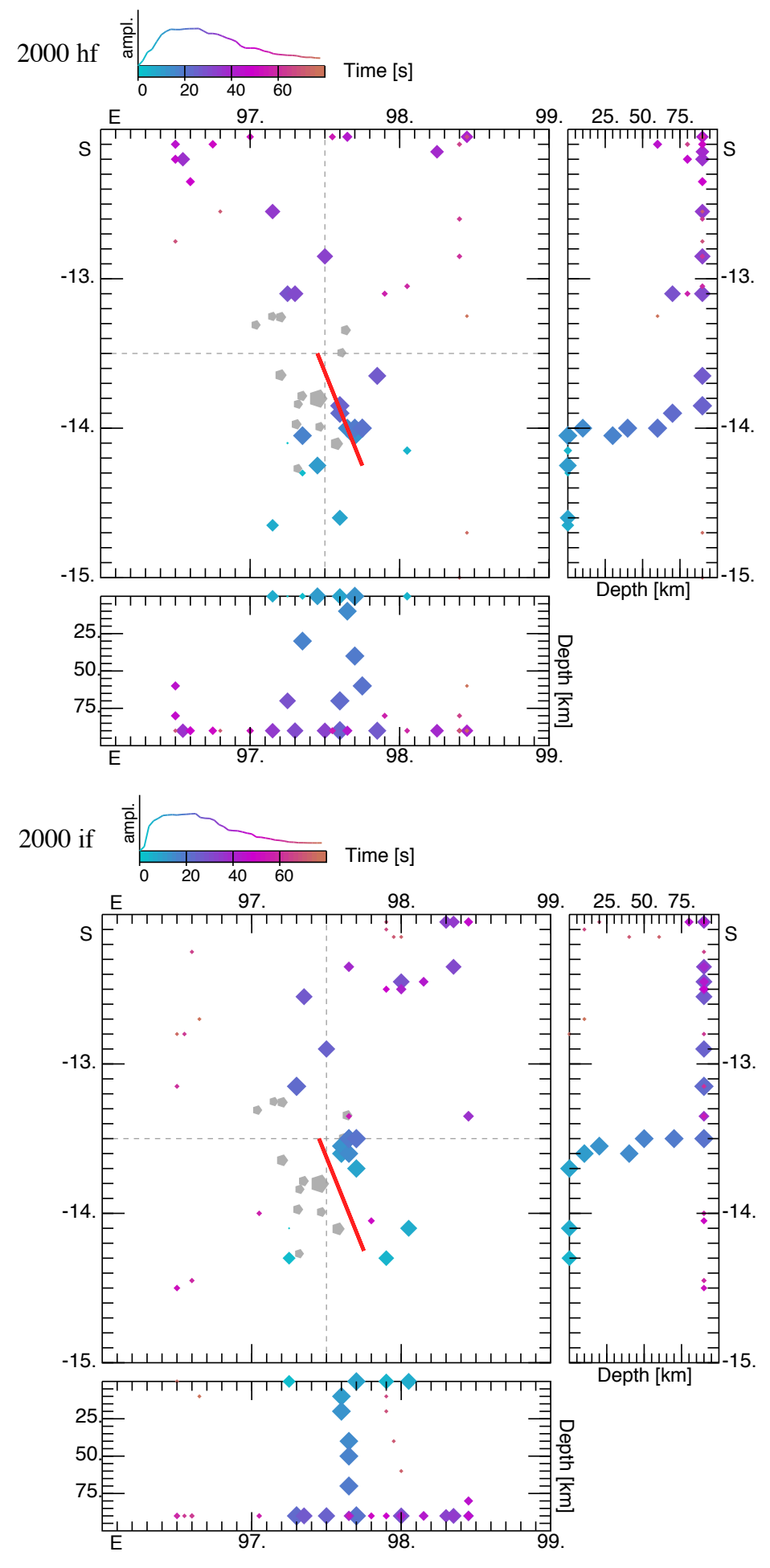

(b)

Figure 7. Map and cross-section view of energy projection results for the Mw 7.9 event on 2000 June 18: (a) high frequency band 0.8-2.0 Hz; (b) intermediate frequency band 0.2-1.0 Hz. As in Figure 6, the evocentres are colour coded as a function of time, and scaled by the size of the estimated energy for the window. The red fault plane is taken from the study of Abercrombie et al. (2003). 
Once again we have indication of early conjugate faulting with a ESE orientation. Though for this event, the pattern of energy migration is clearest in the high-frequency band. The high-frequency energy after $16 \mathrm{~s}$ is mostly linked to the NNW oriented fault plane, but with earlier energy emission to the west. Whereas the intermediate-frequency energy is displaced towards the east. These results are consistent with the two sub-event model of Abercrombie et al. (2003), with the high-frequency energy associated with the main strike-slip event, and the intermediate-frequencies linked to the small second sub-event with reverse faulting at a dip angle of $40^{\circ}$.

In the intermediate-frequency results (Figure $7 b$ ) we also see minor late conjugate faulting at depth to the north and east of the main fault trend with a spatial shift of about $40 \mathrm{~km}$. This patch of energy emission might be linked to the spatially separated second-event postulated by Robinson et al. (2001) from low-frequency $P$ waveform fitting. But, there is no need to make the $50 \mathrm{~km}$ shift to the west for the entire event cluster advocated by these authors to align faulting with mapped topographic features.

Since failure appears to occur through much of the lithosphere, rather than at very shallow depth, the case for such topographic correspondence is not strong. Our results do not suggest that any significant displacement of the hypocentre could be justified.

In both the high-frequency and intermediate frequency results we see indications of a rapid migration of the evocentres to depth but with some dip. This would be consistent with secondary bilateral faulting.

The dominant behaviour in this 2000 event is associated with the trend of the fault plane proposed by Abercrombie et al. (2003). Yet, there is a suggestion that failure may occur on multiply separated fault strands with a similar orientation. The presence of conjugate faulting with a spatially separated component of energy emission is reminiscent of the secondary energy emission for the 2004 December 24 event near the Macquarie ridge (Kennett et al. 2014a). This Mw 8.1 strike-slip event shows high-frequency rupture on a lineation with the same strike as the main event imaged with low-frequency analysis, but displaced about $50 \mathrm{~km}$ to the west.

\section{APRIL 11 EVENTS, Mw 8.6 AND Mw 8.2}

The Mw 8.6 and Mw 8.2 events on 2012 April 11 lie much closer to the subduction zone than the Mw 7 events we have so far considered. The Mw 8.6 event is the largest known intra-plate event and has been the subject of many studies (e.g., Wei et al. 2013, Hill et al. 2015), which reveal conjugate strike-slip faulting and jumping of energy emission to new locations as well as significant energy release at depth. Singh et al. (2017) report the presence of shallow conjugate features in the zone around the epicentre of the Mw 8.2 event using high-resolution bathymetry and seismic reflection data. Left-lateral strike-slip faulting is apparent along reactivated oceanic fracture zones, orientation $\mathrm{N} 7^{\circ} \mathrm{E}$, accompanied by shear zones with strike $\mathrm{N} 294^{\circ} \mathrm{E}$, oblique to the plate fabric.

For the evocentre analysis of the two Mw 8 events, we have used a common large search area (Figures 8,9 ). The larger event is very complex, yet the features that emerge are very similar to the behaviour for the 2000 and 2016 events though on a much larger scale. Subsequent to the Mw 8 events there have been many aftershocks, so we display in Figures 8, 9 events with magnitude greater than 


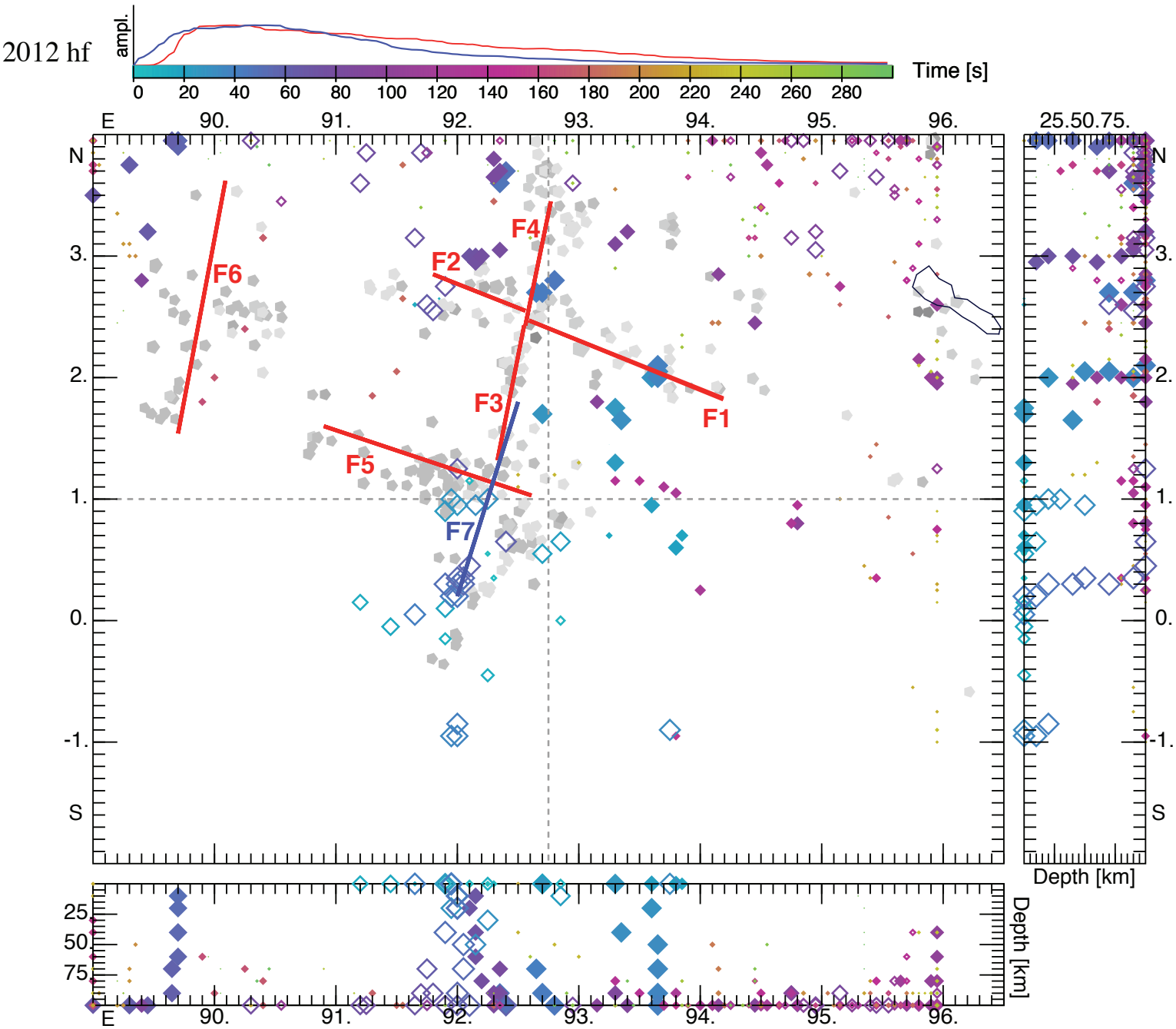

Figure 8. Map and cross-section view of energy projection results for the Mw 8+ events on 2012 April 11 in the high frequency band $0.8-2.0 \mathrm{~Hz}$. The evocentres are colour coded as a function of time, and scaled by the size of the estimated energy for the window. The set of red fault planes for the Mw 8.6 event is taken from Hill et al. (2015), and the blue fault plane for the Mw 8.2 event from Wei et al. (2013) The evocentres for the earlier Mw 8.6 event are shown as solid symbols, with time evolution in red. The evocentres for the subsequent Mw 8.2 event are shown with open symbols, and time evolution in blue. Later events within the search area with magnitude greater than 5 are also displayed in grey tone. These are mostly aftershocks, but include some subduction related events.

5 within the search area, which includes some subduction related events in the NE corner. A number of different models have been proposed for the fault planes for these events. We display in red the fault planes suggested by Hill et al. (2015) from a comprehensive study using both seismological and gedodetic data, and use their numbering system in Figures 8, 9 to aid discussion of the multiple features.

For the Mw 8.6 event we again note significant differences between the high-frequency results (Figure 8 ) and the intermediate-frequency band (Figure 9). The early large energy release in each case 


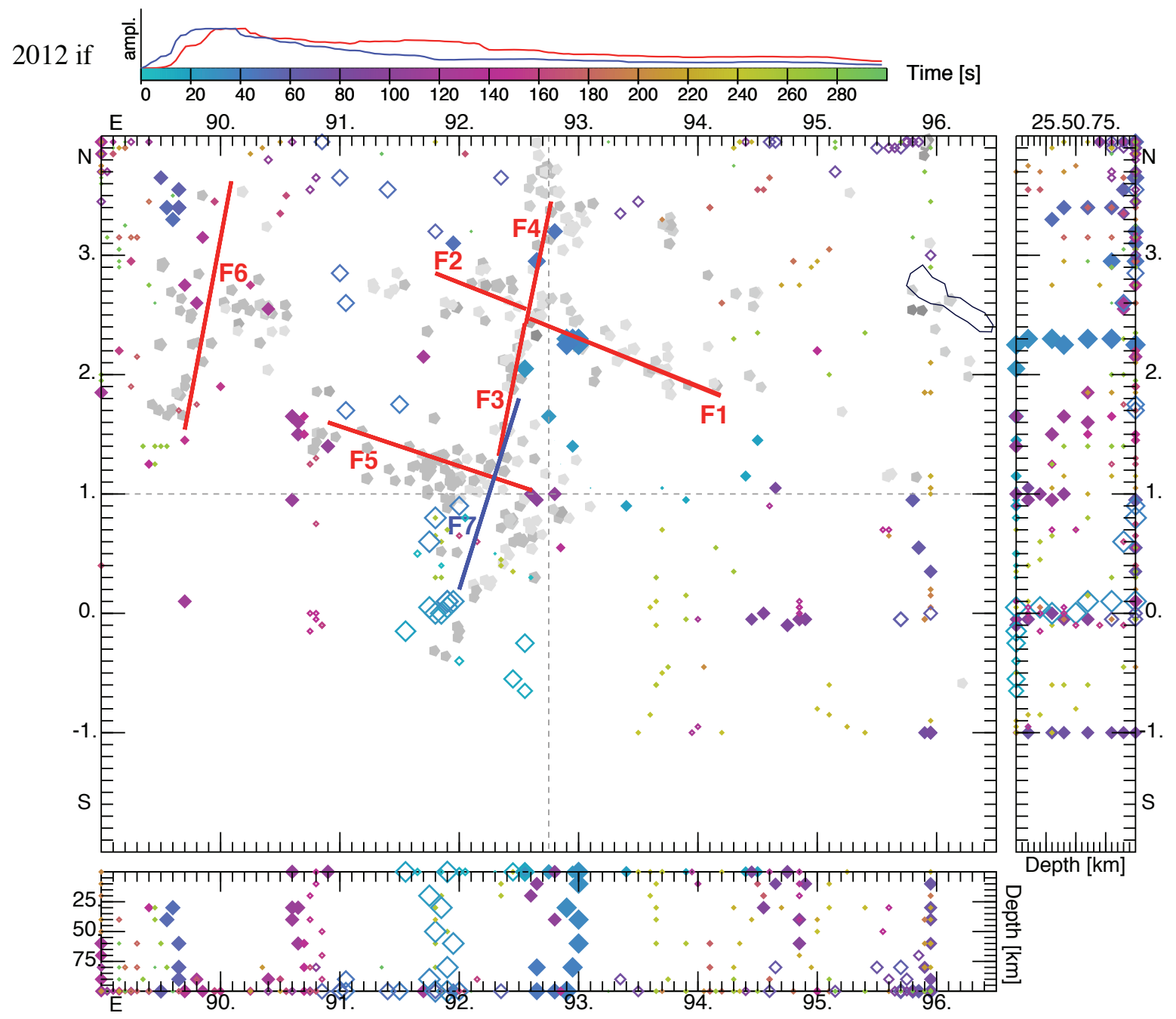

Figure 9. Map and cross-section view of energy projection results for the Mw 8+ events on 2012 April 11 in the intermediate frequency band $0.2-1.0 \mathrm{~Hz}$. The evocentres are colour coded as a function of time, and scaled by the size of the estimated energy for the window. The set of red fault planes for the $\mathrm{Mw} 8.6$ event is taken from Hill et al. (2015), and the blue fault plane for the Mw 8.2 event from Wei et al. (2013) The evocentres for the earlier Mw 8.6 event are shown as solid symbols, with time evolution in red. The evocentres for the subsequent Mw 8.2 event are shown with open symbols, and time evolution in blue. We also display later events within the search area with magnitude greater than 5 , in grey tone. These are mostly aftershocks, but include some subduction related events.

is associated with fault planes F1 and F2, with apparent migration of energy release to depth. For this large and complex event there is a distinct possibility of depth phases at some stations interfering with the $P$ arrivals from other parts of the fault system. This might distort the depth estimates for the position of overall maximum energy release, but will not produce progression to depth. Apparently deeper sources produce early arrivals, whereas the depth phases introduce delay.

As in the model of Hill et al. (2015) fault planes F1 and F2 dominate the energy release up to 80 $\mathrm{s}$ and then the western cluster F6 becomes evident. The high-frequency results favour a north-south 
trend for F6 as in the model of Hill et al. (2015), rather than an east-west orientation as proposed by Meng et al. (2012), Yue et al. (2012). In the intermediate-frequency results (Figure 8b) there is a hint of an east-west extension of rupture near the western end of segment F5. The two clusters of evocentres from 30-50 s on F1 and from 90-110 s at the western end of F5 have a close correspondence with the two point sources representation of Duputel et al. (2012) from W-Phase analysis. The F1 group is significantly stronger matching their analysis.

As in the discussion of the two smaller events, the presence of rapid migration of the evocentres to depth is likely to be associated with bilateral rupture on the different fault segments. For high frequencies we see energy emission relating to segments F1, F4, and in the neighbourhood of F6. Whereas for intermediate frequencies there is extra energy emission at the western end of segment F5.

Even as rupture is progressing in the main $\mathrm{Mw} 8.6$ event, we see isolated centres of energy release associated with distinct events displaced from the main fault-planes, e.g. near $0.1^{\circ} \mathrm{S}, 94.4^{\circ} \mathrm{E}$, and in the SE corner of the search area. Such events would be obscured in long-period analysis and since the waveforms will not be coherent with those from the main event will be suppressed in conventional back-projection techniques. In each case the pattern of evocentres suggest localised bilateral rupture.

The Mw 8.2 aftershock has received less attention than the Mw 8.6 event, but also displays some interesting features. Much of the high-frequency energy release can be associated with the fault-plane proposed by Wei et al. (2013), indicated in blue in Figures 8, 9 (F7). But there are also clear indications of an early conjugate components close to the equator, and near $1^{\circ} \mathrm{S}$. This conjugate element is also present in the intermediate frequency results that also suggest a slight southward extension of the faulting on the main near north-south plane. Some energy release also appears to link to the east-west segment F5 of the Mw 8.6 event. Once again the rapid migration of the evocentres to depth suggest the presence of bilateral rupture.

Alternative views of the evocentre distribution in a 3-D perspective presentation are displayed in Figure A3 in the Appendix.

\section{DISCUSSION AND CONCLUSIONS}

The 3-D evocentre analysis provides an additional tool for investigating source evolution complementing teleseismic analysis of lower frequency waveforms, and back-projection from dense,but azimuthally limited, networks. With good global azimuthal control it is possible to achieve strong spatial localisation in 3-D, and thereby resolve features that may remain blurred when using back-projection from even the densest regional seismic networks.

The evolution of the point of maximum energy release with time provides a good indication of conjugate faulting, and also jump of rupture to separate source segments. For all the these large strike-slip events we see evidence for a component of conjugate faulting, and the possibility of multi-strand faulting for the 2000 event. Thus the apparently unusual features of the $2012 \mathrm{Mw} 8.6$ event, with multiple conjugate faults and energy jumps, appear to be characteristic of these strike-slip events in the Indo-Australian plate offshore from Sumatra. For all these large events we see strong indications of migration of higher-frequency energy emission to depth, with most energy emission within the oceanic mantle. The depth estimates for the evocentres need to be treated with caution 
because of some possible contamination by depth phases, but suggest that failure is occurring though much of the lithosphere.

The stresses associated with subduction along the Andaman-Sumatran arc are oblique to the topographic features, and this stress field can encourage conjugate behaviour exploiting dominantly near north-south faulting linked to the topographic grain, but with near east-west links.

Large patches of lithosphere appear to reach a critical state at the same time so that complex failure follows event initiation, including jumping of the location of rupture. This may well be induced by the arrival of the $P$ wave tipping the stress-balance, as appears to be the case for the $2004 \mathrm{Mw} 8.1$ Macquarie Ridge event (Kennett et al. 2014).

Teleseismic results for the Mw 8.6 event are compatible with significant energy release at depth, (e.g. Hill et al. 2015), but such contributions are commonly penalised in the inversion based on the expectation of shallow brittle failure. The evocentre results suggest that a significant amount of higher-frequency radiation comes from depth. The behaviour suggests that deep-seated initial failure leads ultimately to faulting through the full thickness of the lithosphere. The deepest evocentres lie well within expected ductile regions, suggesting a notable difference between instantaneous and long-term rheology.

Aderhold \& Abercrombie (2016) have made a careful study of $6.0 \leq \mathrm{Mw} \leq 8.0$ events in the Wharton basin using long-period seismic signals. They find that centroid depths are generally located above the $600^{\circ} \mathrm{C}$ isotherm $\left(35-40 \mathrm{~km}\right.$ depth) and that rupture can be confined above the $800^{\circ} \mathrm{C}$ isotherm (45-55 km depth). Only the largest events need deeper rupture. With the $\sim 20 \mathrm{~km}$ systematic depth offset associated with our use of the ak135 reference model, it is clear that the higher frequency results from the evocentre analysis suggest somewhat deeper effects than can explain the low-frequency observations.

The deep seismic profile of Qin \& Singh (2015) near the trench, in the neighbourhood of the major 2012 events, shows the presence of clear listric faults in the oceanic mantle extending to considerable depth $(\sim 45 \mathrm{~km})$, so that deep faulting is indeed possible - though the age is unconstrained. The dips of these features are too shallow to be associated with the ruptures seen in the 2012 events. Very steep faults at depth, are extremely hard to image with reflection seismology because any reflections will reach the surface well beyond the end of any feasible streamer cable. Thus the actual rupture surfaces associated with even large earthquakes could well be missed.

The association of the larger earthquakes off Sumatra with distinctive zones in the shear wavespeed distribution determined from surface wave tomography suggests the presence of variations in physical properties in the Indo-Australian plate, since it is difficult to see how lateral thermal anomalies could be sustained. Localised contrasts in properties could help to concentrate stress and encourage earthquake rupture to span the full thickness of the oceanic lithosphere.

The Wharton Basin events occur within the diffuse zone of breakup of the Indo-Australian plate and a 'patch-work' of physical properties may help to take up the deformation rather than encouraging a concentration on a simple boundary.

For each of the four large strike-slip events there are notable differences in the energy emission patterns between the high-frequency and intermediate-frequency bands, and further between these 
and the results from low-frequency analysis. Separation of higher- and lower-frequency slip is a prominent feature of major megathrust events such as the 2004 Sumatra-Andaman earthquake, the 2011 earthquake off Tohoku, Japan and the 2010 Maule event in Chile (Ye et al. 2016). The present results suggest that separation of rupture effects in frequency is likely to be a general feature of large earthquakes with multiple triggered sub-events.

\section{ACKNOWLEDGMENTS}

The seismic data for the global stations for the evocentre analysis was sourced from the IRIS Data Management Centre in Seattle. Earthquake information was extracted from the catalogues of the Global Earthquake Model (GEM) and International Seismological Centre (ISC).

\section{REFERENCES}

Abercrombie, R.E., Antolik, M. \& Ekström, G., 2003. The June 2000 Mw 7.9 earthquakes south of Sumatra: Deformation in the India-Australia Plate, J. geophys. Res., 108(B1), 2018, doi:10.1029/2001JB000674.

Aderhold, K., \& Abercrombie, R.E., 2016. Seismotectonics of a diffuse plate boundary: Observations off the Sumatra-Andaman trench, J. geophys. Res. Solid Earth, 121, 3462-3478.

Delescluse, M., Chamot-Rooke, N., Cattin, R., Fleitout, L., Trubienko, O. \& Vigny, C., 2012. April 2012 intraoceanic seismicity off Sumatra boosted by the Banda-Aceh megathrust, Nature, 490, 240-245.

Duputel, Z., Kanamori, H., Tsai, V.C., Rivera, L., Meng, L., Ampuero, J.-P. \& Stock, J.M., 2012. The 2012 Sumatra great earthquake sequence, Earth Planet. Sci. Lett., 351-352, 247-257.

Fishwick, S., 2010. Surface wave tomography: Imaging of the lithosphere-asthenosphere boundary beneath central and southern Africa? Lithos, 120, 63-73

Fishwick, S. \& Rawlinson, N., 2012. 3-D structure of the Australian lithosphere from evolving seismic datasets, Austral. J. Earth Sci., 59, 809-826

Hill, E.M., Yue, H., Barbot, S., Lay, T., Taponnier, P., Hermawan, I., Hubbard, J., Bannerjee, P., Feng, L., Natawidjaja, D. \& Sieh, K., 2015. The 2012 Mw 8.6 Wharton Basin sequence: A cascade of great earthquakes generated by near-orthogonal, young, oceanic-mantle faults, J. geophys. Res. Solid Earth, 120, 3723-3747.

Ishii M., Shearer P.M., Houston H. \& Vidale J., 2005. Extent, duration and speed of the 2004 Sumatra-Andaman earthquake imaged by the Hi-net array, Nature, 435, 933-936.

Ishii, M., Kiser, E. \& Geist, E.L., 2013. Mw 8.6 Sumatran earthquake of 11 April 2012: Rare seaward expression of oblique subduction, Geology, 41, 319-322.

Kennett, B.L.N., Engdahl, E.R. \& Buland, R., 1995. Constraints on seismic velocities in the Earth from travel times, Geophys. J. Int., 122, 108-124.

Kennett, B.L.N., Gorbatov, A. \& Spiliopoulos, S., 2014a. Tracking high-frequency seismic source evolution: 2004 Mw 8.1 Macquarie event, Geophys. Res. Lett., 41, doi:10.1002/2013GL058935.

Kennett, B.L.N., Gorbatov, A. \& Spiliopoulos, S., 2014b. Tracking earthquake source evolution in 3-D, Geophys. J. Int., 198, 867-879.

Kiser, E. \& Ishii, M., 2012. Combining seismic arrays to image the high-frequency characteristics of large earthquakes, Geophys. J. Int., 188, 1117-1128.

Krischer, L., Hutko, A. R., van Driel, M., Stähler, S., Trabant, C., and Nissen-Meyer, T. (2017). On- 
demand custom broadband synthetic seismograms. Seismological Research Letters, 88(4) 1127-1140. doi: $10.1785 / 0220160210$

Lay, T., Ye, L., Ammon, C.J., Dunham, A. \& Koper, K.D., 2016. The 2 March 2016 Wharton Basin Mw 7.8 earthquake: High stress drop north-south strike-slip rupture in the diffuse oceanic deformation zone between the Indian and Australian Plates, Geophys. Res. Lett., 43, 7937-7945.

McKenzie, D., Jackson, J. \& Priestley, K., 2005. Thermal structure of oceanic and continental lithosphere, Earth Planet. Sci. Lett., 233, 337-349.

Meng, L., Ampuero, J.-P., Stock, J., Duputel, Z., Luo, Y. \& Tsai, V.C., 2012. Earthquake in a maze: Compressional rupture branching during the $2012 \mathrm{Mw} 8.6$ Sumatra earthquake, Science, 337, 724-726.

Qin, Y. \& Singh, S.C., 2015. Seismic evidence of a two-layer lithospheric deformation in the Indian Ocean. Nature Commun., 6, 8298. doi: 10.1038/ncomms9298.

Robinson, D.P., Henry, C., Das, S. \& Woodhouse, J.H., 2001. Simultaneous rupture along two conjugate planes of the Wharton Basin earthquake, Science, 292, 1145-1148.

Roessler, D., Krueger, F., Ohrnberger, M. \& Ehlert, L., 2010. Rapid characterisation of large earthquakes by multiple broadband arrays, Nat. Hazards Earth Syst Sci., 10, 923-929.

Satriano, C., Kiraly, E., Bernard, P. \& Vilotte, J.-P., 2012. The 2012 Mw 8.6 Sumatra earthquake: Evidence of westward sequential seismic ruptures associated to the reactivation of a N-S ocean fabric, Geophys. Res. Lett., 39, L15302, doi:10.1029/2012GL052387.

Schaeffer, A.J. \& Lebedev, S., 2013. Global shear speed structure of the upper mantle and transition zone, Geophys. J. Int., 194, 417-449.

Singh, S.C., Hananto, N., Qin, Y., Leclerc, F., Avianto, P., Tapponnier, P.E., Carton, H., Wei, S., Nugroho, A.B., Gemilang, W.A., Sieh, K. \& Barbot, S., 2017. The discovery of a conjugate system of faults in the Wharton Basin intraplate deformation zone. Sci. Adv., 3, e1601689. doi: 10.1126/sciadv.1601689.

Suzuki, M. \& Yagi, Y., 2011. Depth dependence of rupture velocity in deep earthquakes, Geophys. Res. Lett., 38, L05308, doi:10.1029/2011GL046807.

Walker, K.T. \& Shearer, P.M., 2009. Illuminating the near-sonic rupture velocities of the intracontinental Kokoxili Mw 7.8 and Denali fault Mw 7.9 strike-slip earthquakes with global P wave back projection imaging, $J$. geophys. Res., 114, B02304, doi:10.1029/2008JB005738.

Wei, S., Helmberger, D. \& Avouac, J.-P., 2013. Modeling the 2012 Wharton basin earthquakes off-Sumatra: Complete lithospheric failure, J. geophys. Res. Solid Earth, 118, 3592-3609.

Ye, L., Lay, T., Kanamori, H. \& Rivera, L. 2016). Rupture characteristics of major and great (Mw > 7.0) megathrust earthquakes from 1990 to 2015: 2. Depth dependence, J. geophys. Res. Solid Earth, 121,845863.

Yue, H., Lay, T. \& Koper, K.D. 2012. En échelon and orthogonal fault ruptures of the 11 April 2012 great intraplate earthquakes, Nature, 490, 245-249.

\section{APPENDIX A: 3-D PERSPECTIVE VIEWS OF EVOCENTRE RESULTS}

In Figure A1 we contrast evocentre estimates for both the high-frequency $(0.8-4.0 \mathrm{~Hz})$ and intermediate-frequency $(0.2-1.0 \mathrm{~Hz})$ bands for the Mw 7.8 event on 2016 March 2. We here display the results with a perspective view in three dimensions, rather than the map view and projected slices used above (Figure 6). We make a connection from each evocentre to its projection on the surface so that depth can be judged. 
(a)
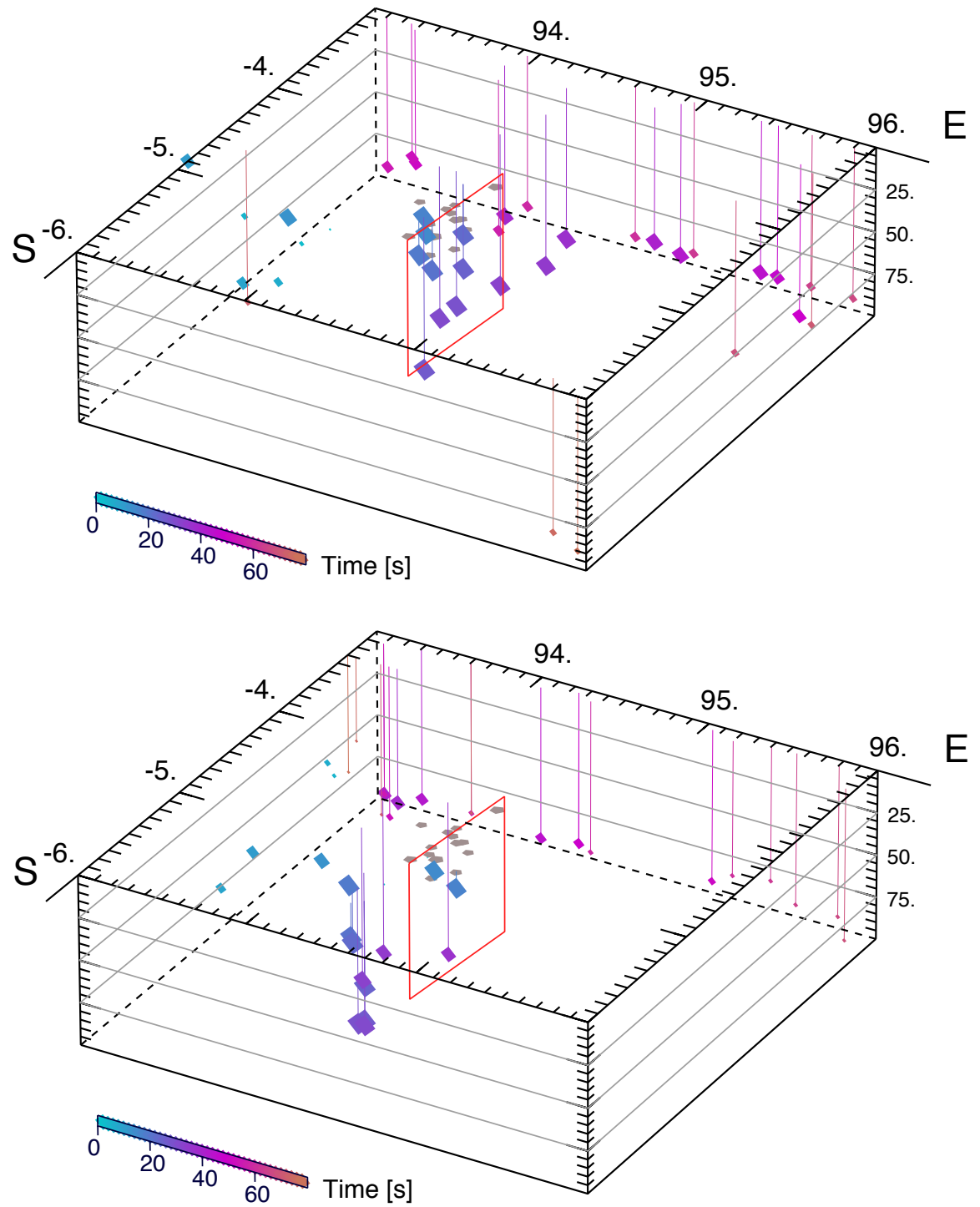

(b)

Figure A1. 3-D view of energy projection results for the Mw 7.8 event on 2016 March 2: (a) high frequency band 0.8-2.0 Hz; (b) intermediate frequency band 0.2-1.0 Hz. The evocentres are colour coded as function of time, and scaled by the size of the estimated energy for the window. A connecting line leads to the surface from each evocentre so the depth can be judged. The red fault plane is taken from the study of Lay et al. (2016).

Figure A2 presents a similar 3-D view for the Mw 7.9 event on 2000 June 18 that lies much further away from the subduction zone. The complex event system on 2012 April 11 is shown in Figure A3, with both the Mw 8.6 event (solid symbols, red faults), and the subsequent Mw 8.2 event (open symbols, blue fault). 
(a)
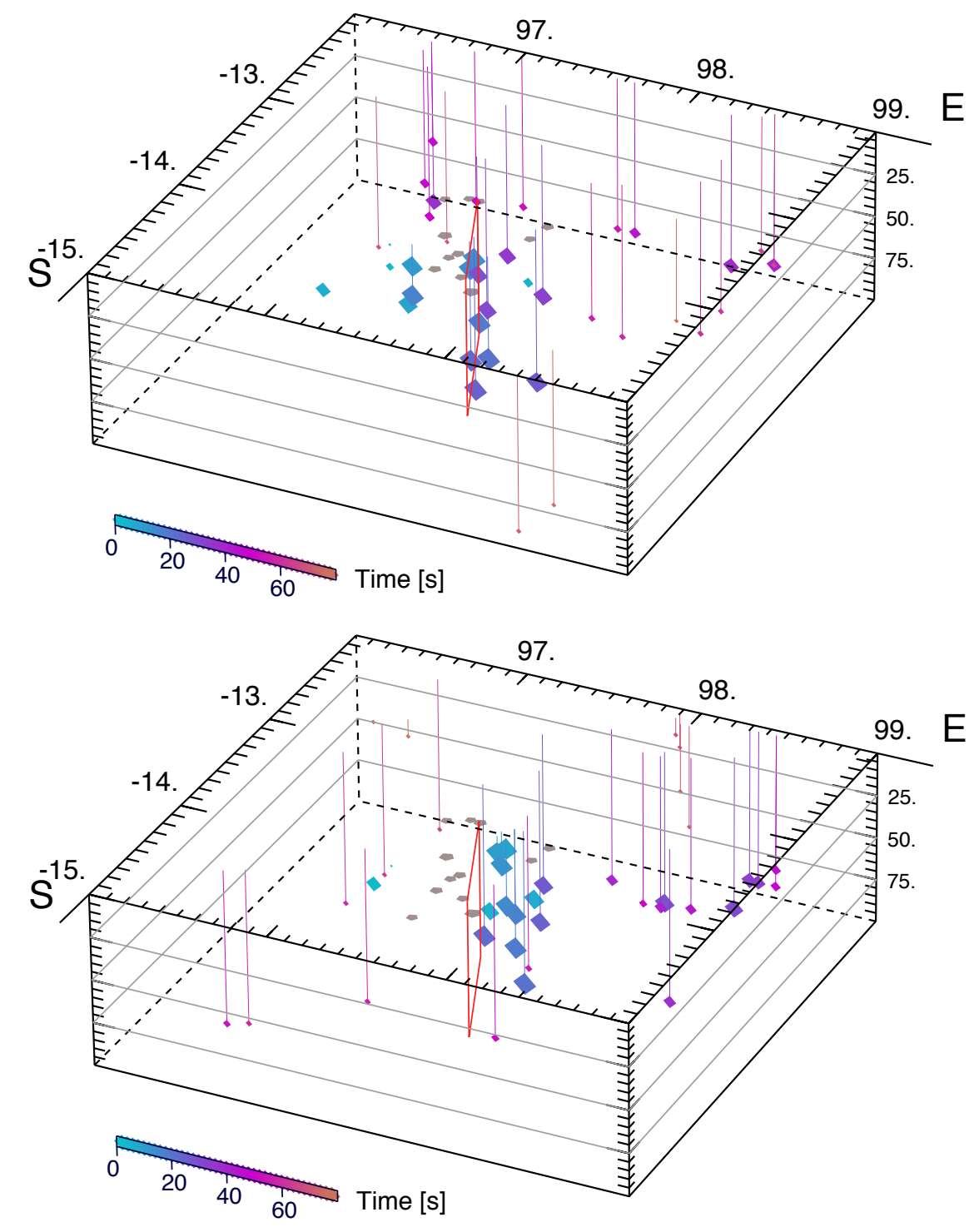

Figure A2. 3-D view of energy projection results for the Mw 7.9 event on 2000 June 18: (a) high frequency band 0.8-2.0 Hz; (b) intermediate frequency band 0.2-1.0 Hz. As in Figure A1, the evocentres are colour coded as a function of time, and scaled by the size of the estimated energy for the window. The red fault plane is taken from the study of Abercrombie et al. (2003). 
(a)
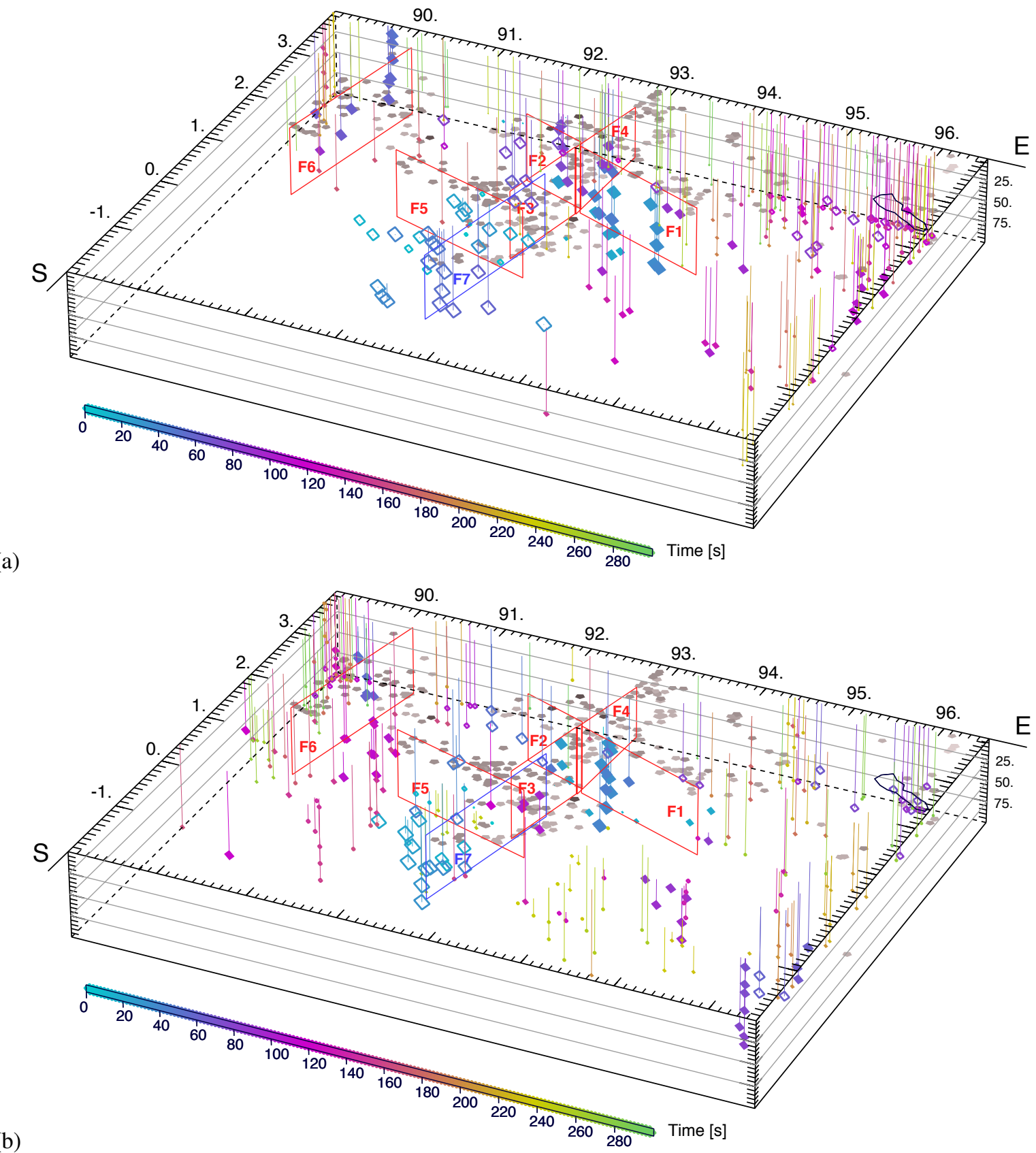

Figure A3. 3-D view of energy projection results for the Mw 8+ events on 2012 April 11: (a) high frequency band $0.8-2.0 \mathrm{~Hz}$; (b) intermediate frequency band $0.2-1.0 \mathrm{~Hz}$. The evocentres are colour coded as a function of time, and scaled by the size of the estimated energy for the window. The set of red fault planes for the Mw 8.6 event is taken from Hill et al. (2015), and the blue fault plane for the Mw 8.2 event from Wei et al. (2013) The evocentres for the earlier Mw 8.6 event are shown as solid symbols, and the evocentres for the later Mw 8.2 event are shown with open symbols, and time evolution in blue. Later events within the search area with magnitude greater than 5 are also displayed in grey tone. These are mostly aftershocks but include some subduction related events.. 